\title{
Syarat Perlu dan Cukup Eksistensi Solusi Permainan Dinamis Dua Orang Berjumlah Nol dengan Ketidakpastian
}

\author{
Muhammad Wakhid Musthofa \\ Program Studi Matematika Fakultas Sains dan Teknologi UIN sunan Kalijaga Yogyakarta, Indonesia.
} Korespondensi; Muhammad Wakhid Musthofa, Email: mwakhid_m@yahoo.com

\begin{abstract}
Abstrak
Artikel ini akan membahas penurunan syarat perlu dan syarat cukup agar permainan dinamis linear kuadratis dua pemain berjumlah nol dengan kehadiran ketidakpastian pada sistem mempunyai strategi optimal robust sebagai solusi optimalnya. Ide untuk menyelesaikannya adalah dengan mendefinisikan dua buah permainan dinamis sedemikian sehingga ketidakpastian pada sistem hanya terjadi untuk salah satu pemainnya saja.
\end{abstract}

Kata Kunci: permainan dinamis linear kuadratis; ketidakpastian pada sistem; solusi optimal robust

\begin{abstract}
This article will discuss the reduction of the necessary and sufficient conditions so that the quadratic linear dynamic game of two players totals zero with the presence of uncertainty in the system having an optimal robust strategy as the optimal solution. The idea to solve this is to define two dynamic games so that uncertainty in the system only occurs for one of the players.
\end{abstract}

Keywords: quadratic linear dynamic game; uncertainty in the system; Robust optimal solution.

\section{Pendahuluan}

Permainan dinamis adalah bagian dari pemodelan matematika yang menggambarkan situasi persaingan antar pihak yang dibingkai dalam suatu sistem dinamik. Pihak yang bersaing dapat berupa perusahaan, negara, institusi pemerintahan maupun individu (Haurie et al 2012, Basar dan Olsder 1999). Masingmasing pihak berusaha untuk merealisasikan tujuannya dengan menentukan strategi terbaik dengan bentuk mengendalikan sistem dinamiknya. Dalam model matematika, permainan dinamis disajikan dalam bentuk pasangan persamaan sistem dinamik dan fungsi biaya. Jika sistem dinamiknya berupa sistem linear dan fungsi biayanya berupa fungsi kuadratik maka permainan dinamisnya disebut bertipe linear kuadratik (Engwerda, 2005). Aplikasi dari permainan dinamis dapat dijumpai dalam masalah ekonomi, pemasaran produk, manajemen resiko, manajemen lingkungan dan persaingan senjata antar negara (Dockner et al 2000, Jorgensen dan Zaccour 2004).

Permainan dinamis yang dibahas dalam artikel ini adalah permainan dinamis dua pemain berjumlah nol (two-person zero-sum game) yang bertipe linear kuadratik yang mengakomodasi keberadaan ketidakpastian pada sistem dinamiknya. Ketidakpastian (uncertainty) adalah suatu hal yang hampir pasti dialami oleh semua sistem. Ketidakpastian pada sistem dapat berasal dari gangguan eksternal sistem (disturbance), penyederhanaan sistem, dan dinamisasi sistem yang terus menerus berubah-ubah terhadap waktu (Kaynak dan Denker 2010, Zhou dan Doyle 1998). Kehadiran ketidakpastian pada sistem membuat para pemain tidak dapat menggunakan strategi biasa, dikarenakan matriks-matriks yang terlibat dalam sistem tidak dapat diketahui dengan pasti nilai eksaknya. Sebagai gantinya, para pemain harus menggunakan strategi robust. Sehingga pencarian strategi robust bagi para pemain merupakan permasalahan utama dalam permainan dinamis dengan ketidakpastian.

Artikel ini akan mencari syarat perlu dan cukup eksistensi strategi optimal robust untuk permainan dinamis dengan ketidakpastian. Dalam rangka mencari strategi optimal tersebut akan didefinisikan dua 
buah permainan dinamis dengan ketidakpastian hanya melekat pada salah satu pemain. Selanjutnya, dengan menggunakan hasil dari Ho et al (1965) dapat diturunkan syarat perlu dan cukup eksistensi strategi optimal robust tersebut. van den Broek (2001) juga telah mencari eksistensi strategi optimal robust yang disebut sebagai robust equilibria namun pada ketidakpastian sistem yang terbatas dan menggunakan cara yang berbeda.

Artikel ini disajikan dengan runtutan alur sebagai berikut. Setelah pendahuluan, bagian kedua dari makalah ini menyajikan konsep permainan dinamis pada sistem nominal. Berdasar konsep tersebut, bagian ketiga artikel ini menyajikan konsep permainan dinamis dengan ketidakpastian sebagai pengembangan dari konsep sebelumnya. Pada bagian ini juga disebutkan permaslahan utama yang akan diselesaikan dalam artikel ini. Selanjutnya, bagian keempat mengulas ide solusi dari permasalahan yaitu menurunkan syarat perlu dan cukup eksistensi strategi optimal robust untuk permainan dinamis dengan ketidakpastian. Teorema eksistensi syarat perlu dan cukup disajikan pada bagian kelima. Terakhir, bagian enam menyimpulkan isi artikel dan memberikan masalah terbuka bagi penelitian selanjutnya.

\section{Permainan Dinamis Sistem Nominal}

Diberikan permainan dinamis linear kuadratik dua orang berjumlah nol yang didefinisikan pada suatu sistem dinamik

$$
\dot{\xi}=X \xi+Y_{1} \alpha+Y_{2} \beta+K \eta
$$

dengan $\xi$ sebagai variabel state untuk sistem (1), $X, Y_{1}, Y_{2}, K$ adalah matriks-matiks dengan dimensi yang bersesuaian, $\alpha$ menyatakan strategi untuk pemain pertama, $\beta$ adalah strategi untuk pemain kedua, dan $\eta$ adalah noise bagi sistem (1). Pemain pertama bertujuan meminimalkan fungsi biaya kuadratik untuk waktu berhingga (finite time horizon) yang disajikan oleh persamaan

$$
L(\alpha, \beta)=R\left\{\xi^{T} H_{T} \xi+\int_{0}^{T}\left(\xi^{T} H \xi+\alpha^{T} M \alpha-\beta^{T} N \beta\right) d t\right\}
$$

dengan $H_{T}$ dan $H$ merupakan matriks simetris dan definit nonnegatif, matriks $M, N$ simetris dan definit positif, dan $T$ menyatakan waktu akhir dari sistem (1). Sedangkan pemain kedua bertujuan memaksimalkan fungsi biaya (2). Masalah yang ingin diselesaikan adalah mencari pasangan strategi optimal $\alpha^{*}$ dan $\beta^{*}$ yang mnimimalkan fungsi biaya (2). Solusi dari masalah ini telah disajikan oleh Ho et al (1965) dalam lemma berikut.

\section{Lemma 1.}

Strategi optimal untuk permainan dinamis sistem nominal (1) dengan fungsin biaya (2) berupa titik sadel (saddle ponit)

$$
\begin{gathered}
\alpha^{*}(t)=-M^{-1} Y_{1} A(t) \xi(t) \\
\beta^{*}(t)=N^{-1} Y_{2} A(t) \xi(t),
\end{gathered}
$$

dan nilai dari permainan diberikan oleh persamaan

$$
L\left(\alpha^{*}, \beta^{*}\right)=m_{0}^{T} A(0) m_{0}+\operatorname{tr} A(0) M(0)+\int_{0}^{T} \operatorname{tr}\left[A(t) K C(t) K^{T}\right] d t
$$

dengan $A=A^{T}>0$ merupakan solusi dari persamaan diferensial Riccati

$$
\dot{A}+A X+X^{T} A-A\left[Y_{1} M^{-1} Y_{1}^{T}-Y_{2} N^{-1} Y_{2}^{T}\right] A+H=0 ; \quad A(T)=H_{T} .
$$

\section{Permainan Dinamis dengan Ketidakpastian}

Permainan dinamis linear kuadratis dua orang berjumlah nol dengan mengakomodasi kehadiran ketidakpastian pada sistem merupakan modifikasi dari permainan dinamis sistem nominal dengan 
menambahkan variabel ketidakpastian pada sistem dinamiknya. Secara matematis, permainan ini didefinisikan pada sistem dinamis

$$
\dot{\xi}=(X+\nabla X) \xi+\left(Y_{1}+\nabla Y_{1}\right) \alpha+\left(Y_{2}+\nabla Y_{2}\right) \beta+K \eta
$$

dengan $\nabla X, \nabla Y_{1}, \nabla Y_{2}$ merupakan matriks-matriks ketidakpastian yang bergantung waktu pada sistem yang memenuhi

$$
\nabla X=P_{0} Q_{0}(t) R_{0}, \nabla Y_{1}=P_{1} Q_{1}(t) R_{1}, \text { dan } \nabla Y_{2}=P_{2} Q_{2}(t) R_{2}, \quad \forall t>0,
$$

dengan $P_{i}, R_{i}, i=1,2$ adalah matriks-matriks konstan bernilai real yang diketahui dengan dimensi yang sesuai, dan $Q_{i}, i=1,2$ menyatakan parameter ketidakpastian dari sistem yang memenuhi

$$
Q_{i}^{T} Q_{i} \leq I .
$$

Pemain pertama ingin meminimalkan fungsi biaya kuadratik (2), sedangkan sebaliknya pemain kedua ingin memaksimalkan fungsi biaya tersebut.

Terdapatnya ketidakpastian dalam permainan dinamis $(4,2)$ menyebabkan solusi optimal permainan dalam bentuk titik sadel sebagaimana dalam persamaan (3) tidak dapat ditemukan. Untuk menyelesaikan masalah tersebut didefinisikan strategi optimal robust sebagai berikut.

\section{Definisi 1.}

Diberikan permainan dinamis yang disertai dengan ketidakpastian pada sistem yang disajikan dengan persamaan dinamik (4) dan fungsi biaya (2). Suatu pasangan strategi $\left(\alpha^{*}, \beta^{*}\right)$ untuk permainan dinamis $(4,2)$ disebut strategi optimal robust jika terdapat dua nilai skalar $L_{-}^{*}$ dan $L_{+}^{*}$ sedemikian sehingga dua buah pertidaksamaan berikut dipenuhi

$$
\min _{\alpha} L\left(\alpha, \beta^{*}\right) \geq L_{-}^{*}, \quad \max _{\beta} L\left(\alpha^{*}, \beta\right) \leq L_{+}^{*} .
$$

Pada permainan dinamis $(4,2)$, jika kedua pemain menggunakan strategi optimal robust $\left(\alpha^{*}, \beta^{*}\right)$ maka untuk semua state $\xi$ dan untuk suatu ketidakpastian yang diperkenankan bagi sistem $\nabla X, \nabla Y_{1}, \nabla Y_{2}$, dipenuhi pertidaksamaan berikut

$$
L_{-}^{*} \leq L\left(\alpha^{*}, \beta^{*}\right) \leq L_{+}^{*}
$$

dengan $L_{-}^{*} \leq L_{+}^{*}$. Selanjutnya nilai skalar $L_{-}^{*}$ disebut nilai atas permainan dan $L_{+}^{*}$ disebut nilai bawah permainan.

Berdasarkan Definisi 1 di atas, jika pemain pertama menggunakan strategi optimal robust maka ia tidak akan pernah menderita kekalahan melebihi nilai $L_{+}^{*}$, sedangkan untuk pemain kedua jika ia menggunakan strategi optimal robust maka ia dapat menjamin pendapatannya tidak kurang dari $L_{-}^{*}$. Untuk itu, perlu dicari syarat perlu dan syarat cukup eksistensi dari strategi optimal robust sehingga permainan dinamis $(4,2)$ mempunyai penyelesaian optimal.

\section{Konstruksi 2 Permainan Dinamis}

Ide untuk mencari syarat perlu dan syarat cukup eksistensi strategi optimal robust untuk permainan dinamis $(4,2)$ adalah dengan membentuk dua buah permainan dinamis linear kuadratis yang difungsikan sebagai alat bantu. Pembentukan permainan dinamis ini dimaksudkan untuk memecah keberadaan ketidakpastian pada sistem, yang pada awalnya ketidakpastian muncul pada dua pihak pemain menjadi hanya muncul pada satu pihak pemain saja. Hal tersebut disajikan dengan dua permasalahan permainan dinamis berikut.

Masalah 1. Permainan dinamis antara pemain pertama dengan strategi $\alpha$ melawan pemain kedua dengan strategi $\gamma^{T}=\left(\begin{array}{ll}\beta & \lambda\end{array}\right)^{T}$. Berarti, dalam hal ini ketidakpastian hanya terjadi pada strategi untuk pemain kedua saja. Permainan ini dapat disajikan dengan persamaan dinamik 


$$
\dot{\xi}=X \xi+Y_{1} \alpha+\left(\begin{array}{ll}
Y_{2} & P
\end{array}\right) \gamma+K \eta
$$

dengan $P=\left[\begin{array}{lll}P_{0} & P_{1} & P_{2}\end{array}\right]$ dan $\lambda=\left[\begin{array}{l}Q_{0}(t) R_{0} \xi \\ Q_{1}(t) R_{1} \xi \\ Q_{2}(t) R_{2} \xi\end{array}\right]$. Fungsi biaya untuk permainan dinamis ini diberikan oleh persamaan

$$
L_{+}(\alpha, \gamma)=R\left\{\xi^{T} H_{T} \xi+\int_{0}^{T}\left(\xi^{T} H_{+} \xi+\alpha^{T} M_{+} \alpha-\gamma^{T} N_{+} \gamma\right) d t\right\}
$$

dengan $H_{+}=H+\varepsilon_{0}^{2} R_{0}^{T} R_{0}, \quad M_{+}=M+\varepsilon_{1}^{2} R_{1}^{T} R_{1}$, dan

$$
N_{+}=\left[\begin{array}{cccc}
N-\varepsilon_{2}^{2} R_{2}^{T} R_{2} & 0 & 0 & 0 \\
0 & \varepsilon_{0}^{2} I & 0 & 0 \\
0 & 0 & \varepsilon_{1}^{2} I & 0 \\
0 & 0 & 0 & \varepsilon_{2}^{2} I
\end{array}\right]
$$

untuk suatu skalar $\varepsilon_{i}>0, i=1,2$.

Didefinisikan $\lambda_{0}=Q_{0}(t) R_{0} \xi, \quad \lambda_{1}=Q_{1}(t) R_{1} \xi$, dan $\lambda_{2}=Q_{2}(t) R_{2} \xi$. Berdasarkan Persamaan (5) diperoleh

$$
\lambda_{0}^{T} \lambda_{0} \leq\left(R_{0} \xi\right)^{T}\left(R_{0} \xi\right), \lambda_{1}^{T} \lambda_{1} \leq\left(R_{1} \alpha\right)^{T}\left(R_{1} \alpha\right) \text {, dan } \lambda_{2}^{T} \lambda_{2} \leq\left(R_{2} \beta\right)^{T}\left(R_{2} \beta\right) .
$$

Selanjutnya, fungsi biaya (7) dapat disajikan sebagai

$$
\begin{aligned}
L_{+}(\alpha, \gamma)= & R\left\{\xi^{T} H_{T} \xi+\int_{0}^{T}\left(\xi^{T} H \xi+\alpha^{T} M \alpha-\beta^{T} N \beta\right) d t\right\} \\
& +R\left\{\int _ { 0 } ^ { T } \left\{\varepsilon_{0}^{2}\left[\lambda_{0}^{T} \lambda_{0}-\left(R_{0} \xi\right)^{T}\left(R_{0} \xi\right)\right]+\varepsilon_{1}^{2}\left[\lambda_{1}^{T} \lambda_{1}-\left(R_{1} \alpha\right)^{T}\left(R_{1} \alpha\right)\right]\right.\right. \\
& \left.\left.+\varepsilon_{2}^{2}\left[\lambda_{2}^{T} \lambda_{2}-\left(R_{2} \beta\right)^{T}\left(R_{2} \beta\right)\right]\right\} d t\right\} .
\end{aligned}
$$

Dikarenakan $\lambda_{0}, \lambda_{1}$, dan $\lambda_{1}$ memenuhi Persamaan (8) maka persamaan berikut dipenuhi

$$
L_{+}(\alpha, \gamma) \geq L(\alpha, \beta),
$$

dengan $L(\alpha, \beta)$ merupakan nilai dari fungsi biaya (2). Persamaan (9) dapat ditulis sebagai

$$
L_{+}(\alpha, \beta, \lambda) \geq L(\alpha, \beta) \text {. }
$$

Berdasarkan Persamaan (10) didapat

$$
\max _{\beta} L_{+}(\alpha, \beta, \lambda) \geq \max _{\beta} L(\alpha, \beta),
$$

Dan

$$
\max _{\lambda} \max _{\beta} L_{+}(\alpha, \beta, \lambda) \geq \max _{\beta} L(\alpha, \beta)
$$

Persamaan (11) dapat ditulis sebagai

$$
\max _{\gamma} L_{+}(\alpha, \beta, \lambda) \geq \max _{\beta} L(\alpha, \beta) .
$$

Jika $\alpha^{*}$ adalah strategi optimal bagi pemain pertama dalam permainan dinamis $(6,7)$, maka $\alpha^{*}$ mempunyai bentuk (Basar dan Berhard 2000)

$$
\alpha^{*}=\min _{\alpha} \max _{\beta} L(\alpha, \beta)
$$

Sehingga berdasarkan persamaan (9) dan (12) maka dipenuhi

$$
\min _{\alpha} \max _{\gamma} L_{+}(\alpha, \gamma)=L_{+}^{*} \geq \min _{\alpha} \max _{\beta} L(\alpha, \beta) \text {. }
$$


Jadi, untuk Masalah 1 di atas, dipenuhi pertidaksamaan

$$
\max _{\beta} L\left(\alpha^{*}, \beta\right) \leq L_{+}^{*},
$$

untuk semua ketidakpastian yang diperkenankan bagi sistem.

Masalah 2. Permainan dinamis antara pemain pertama dengan strategi $\delta^{T}=\left(\begin{array}{ll}\alpha & \lambda\end{array}\right)^{T}$ melawan pemain kedua dengan strategi $\beta$. Berarti, dalam hal ini ketidakpastian hanya terjadi pada strategi untuk pemain pertama saja. Permainan ini dapat disajikan dengan persamaan dinamik

$$
\dot{\xi}=X \xi+\left(\begin{array}{ll}
Y_{1} & P
\end{array}\right) \delta+Y_{2} \beta+K \eta,
$$

dengan fungsi biaya untuk pemain pertama disajikan oleh persamaan

$$
L_{-}(\delta, \beta)=R\left\{\xi^{T} H_{T} \xi+\int_{0}^{T}\left(\xi^{T} H_{-} \xi+\delta^{T} M_{-} \delta-\beta^{T} N_{-} \beta\right) d t\right\}
$$

dengan $H_{-}=H-\varepsilon_{0}^{-2} R_{0}^{T} R_{0}, \quad N_{-}=N+\varepsilon_{2}^{-2} R_{2}^{T} R_{2}$, dan

$$
M_{-}=\left[\begin{array}{cccc}
M-\varepsilon_{1}^{-2} R_{1}^{T} R_{1} & 0 & 0 & 0 \\
0 & \varepsilon_{0}^{-2} I & 0 & 0 \\
0 & 0 & \varepsilon_{1}^{-2} I & 0 \\
0 & 0 & 0 & \varepsilon_{2}^{-2} I
\end{array}\right]
$$

untuk suatu skalar $\varepsilon_{i}>0, i=1,2$. Fungsi biaya kuadratik (14) dapat ditulis sebagai

$$
\begin{aligned}
L_{-}(\delta, \beta)= & R\left\{\xi^{T} H_{T} \xi+\int_{0}^{T}\left(\xi^{T} H \xi+\alpha^{T} M \alpha-\beta^{T} N \beta\right) d t\right\} \\
& -R\left\{\int _ { 0 } ^ { T } \left\{\varepsilon_{0}^{2}\left[\lambda_{0}^{T} \lambda_{0}-\left(R_{0} \xi\right)^{T}\left(R_{0} \xi\right)\right]+\varepsilon_{1}^{2}\left[\lambda_{1}^{T} \lambda_{1}-\left(R_{1} \alpha\right)^{T}\left(R_{1} \alpha\right)\right]\right.\right. \\
& \left.\left.+\varepsilon_{2}^{2}\left[\lambda_{2}^{T} \lambda_{2}-\left(R_{2} \beta\right)^{T}\left(R_{2} \beta\right)\right]\right\} d t\right\} .
\end{aligned}
$$

Selanjutnya, dikarenakan $\lambda_{0}, \lambda_{1}$, dan $\lambda_{1}$ memenuhi Persamaan (8) maka persamaan berikut dipenuhi

$$
L_{-}(\delta, \beta) \leq L(\alpha, \beta)
$$

dengan $L(\alpha, \beta)$ merupakan nilai dari fungsi biaya (2). Persamaan (15) dapat ditulis sebagai

$$
L_{-}(\lambda, \alpha, \beta) \leq L(\alpha, \beta) \text {. }
$$

Berdasarkan Persamaan (16) didapat

$$
\min _{\alpha} L_{-}(\lambda, \alpha, \beta) \leq \min _{\alpha} L(\alpha, \beta)
$$

Dan

$$
\min _{\lambda} \min _{\alpha} L_{-}(\lambda, \alpha, \beta) \leq \min _{\alpha} L(\alpha, \beta)
$$

Persamaan (17) dapat ditulis sebagai

$$
\min _{\delta} L_{-}(\delta, \beta) \leq \min _{\alpha} L(\alpha, \beta)
$$

Jika $\beta^{*}$ adalah strategi optimal bagi pemain kedua dalam permainan dinamis $(13,14)$, maka $\beta^{*}$ mempunyai bentuk (Basar dan Berhard 2000)

$$
\beta^{*}=\max _{\beta} \min _{\alpha} L(\alpha, \beta) .
$$

Sehingga berdasarkan persamaan (15) dan (18) maka dipenuhi

$$
\max _{\beta} \min _{\delta} L_{-}(\delta, \beta)=L_{-}^{*} \leq \max _{\beta} \min _{\alpha} L(\alpha, \beta) .
$$

Jadi, untuk Masalah 2 di atas, dipenuhi pertidaksamaan 


$$
\min _{\alpha} L\left(\alpha, \beta^{*}\right) \geq L_{-}^{*},
$$

untuk semua ketidakpastian yang diperkenankan.

Solusi dari Masalah 1 dan Masalah 2 di atas dapat diperoleh dengan menggunakan Lemma 1.

\section{Syarat Perlu dan Cukup Permainan Dinamis dengan Ketidakpastian}

Pada bagian ini akan diturunkan syarat perlu dan syarat cukup eksistensi strategi optimal robust sebagai solusi dari permainan dinamis $(4,2)$. Berdasarkan hasil yang telah diperoleh dalam Masalah 1 dan Masalah 2, dan berdasarkan Lemma 1, diperoleh teorema berikut.

\section{Teorema 1.}

Diberikan permainan dinamis dua pemain berjumlah nol yang disertai dengan ketidakpastian yang disajikan dengan persamaan dinamik (4) dan fungsi biaya (2). Strategi optimal robust untuk permainan dinamis $(4,2)$ adalah

$$
\begin{gathered}
\alpha^{*}=-M_{+}^{-1} Y_{1} A_{+}(t) \xi(t) \\
\beta^{*}=N_{-}^{-1} Y_{2} A_{-}(t) \xi(t)
\end{gathered}
$$

jika dan hanya jika terdapat skalar $\varepsilon_{i}>0, i=1,2$ yang menghasilkan matriks-matriks $H_{-}, N_{+}, M_{-}$ yang definit positif, dengan $A_{+}=A_{+}^{T}>0$ memenuhi persamaan diferensial Riccati

$$
\dot{A}_{+}+A_{+} X+X^{T} A_{+}+H_{+}-A_{+}\left[Y_{1} M_{+}^{-1} Y_{1}^{T}-\left(\begin{array}{ll}
Y_{2} & P
\end{array}\right) N_{+}^{-1}\left(\begin{array}{ll}
Y_{2} & P
\end{array}\right)^{T}\right] A_{+} \leq 0
$$

dan $A_{-}=A_{-}^{T}>0$ memenuhi persamaan diferensial Riccati

$$
\dot{A}_{-}+A_{-} X+X^{T} A_{-}+H_{-}-A_{-}\left[\left(\begin{array}{ll}
Y_{1} & P
\end{array}\right) M_{-}^{-1}\left(\begin{array}{ll}
Y_{1} & P
\end{array}\right)^{T}-Y_{2} N_{-}^{-1} Y_{2}^{T}\right] A_{-} \geq 0 .
$$

Lebih lanjut, nilai dari permainan dinamis tersebut adalah $L$ yang memenuhi pertidaksamaan

$$
L_{-}^{*}(\alpha, \beta) \leq L(\alpha, \beta) \leq L_{+}^{*}(\alpha, \beta)
$$

dengan $L_{-}^{*}(\alpha, \beta)$ merupakan nilai bawah permainan dan diberikan oleh persamaan

$$
L_{-}^{*}(\alpha, \beta)=k_{0}^{T} A_{-}(0) k_{0}+\operatorname{tr} A_{-}(0) M_{0}+\int_{0}^{T} \operatorname{tr}\left[A_{-}(t) K C(t) K^{T}\right] d t
$$

dan $L_{-}^{*}(\alpha, \beta)$ merupakan nilai atas permainan dan diberikan oleh persamaan

$$
L_{+}^{*}(\alpha, \beta)=k_{0}^{T} A_{+}(0) k_{0}+t r A_{+}(0) M_{0}+\int_{0}^{T} \operatorname{tr}\left[A_{+}(t) K C(t) K^{T}\right] d t .
$$

Bukti:

Persamaan (19), (21), dan (24) diperoleh dengan menyelesaikan Masalah 1 dengan menggnakan Lemma 1. Sedangkan Persamaan (20), (22), dan (23) diperoleh dengan menyelesaikan Masalah 2 dengan menggnakan Lemma 1.

\section{Kesimpulan}

Dalam artikel ini telah diturunkan syarat perlu dan syarat cukup permainan dinamis linear kuadratis dua pemain berjumlah nol dengan kehadiran ketidakpastian pada sistem. Dapat dilihat pada Teorema 1 bahwa dalam menentukan syarat perlu dan cukup pada permainan tersebut eksistensi skalar $\varepsilon_{i}>0, \quad i=1,2$ dan solusi dari persamaan diferensial Riccati (21) dan (22) memegang peranan yang cukup penting. Dua hal inilah yang akan menyusun strategi optimal robust sebagai solusi dari permainan dinamis tersebut.

Pembahasan dalam artikel ini masih terbatas pada permainan dinamis fungsi kontinu dan pada domain waktu yang berhingga (finite time horizon). Sehingga pengembangan solusi permainan dinamis 
baik untuk fungsi diskret maupun untuk domain waktu yang takberhingga (infinite time horizon) merupakan masalah terbuka yang dapat diteliti lebih lanjut.

\section{Referensi}

[1] Basar, T. dan Bernhard, P. $H_{\infty}$ Optimal Control and Related Minimax Design Problem, Modern Birkhuser Classics, Boston, 1995.

[2] Basar, T. and Olsder, G. J. Dynamic Noncooperative Game Theory, Academic Press SIAM, New York, 1999.

[3] Broek, v. d. Uncertainty in Differential Game, Ph.D Thesis, Tilburg University, Netherlands, 2001.

[4] Dockner, E., Jorgensen, S., Long, N. v. and Sorger, G. Differential Games in Economic and Management Science, Cambridge University Press, Cambridge, 2000.

[5] Engwerda, J. C. Linear Quadratic Dynamic Optimization and Differential Games, John Wiley \& Sons, West Sussex, 2005.

[6] Haurie, A., Krawczyk, J. dan Zaccour, G. Games and Dynamic Games, Vol. 1, World Scientific Publishing Company, Singapore, 2012.

[7] Ho, Y. C., Bryson, A. E., dan Baron, S. Differential Games and Optimal Pursuit-Evasion Strategies, IEEE Transaction on Automatic Control, AC-10, 1965.

[8] Jorgensen, S. dan Zaccour, G. Differential Games in Marketing, Springer, 2004.

[9] Kaynak, O. dan Denker, A. Discrete-time Sliding Mode Control in the Presence of System Uncertainty, International Journal of Control, vol. 57, no. 5, 2010.

[10] Zhou, K. dan Doyle, J. C. Essentials of Robust Control, Prentice-Hall, New Jersey, 1998. 
THIS PAGE INTENTIONALLY LEFT BLANK 